\title{
A figura astuta da igualdade no discurso da Justiça Restaurativa ${ }^{1}$
}

\section{The astute figure of equality on Restorative Justice discourse}

\author{
Betina Schuler ${ }^{2}$ \\ Paula Correa Henning ${ }^{3}$
}

\begin{abstract}
RESUMO
Este artigo problematiza o conceito de igualdade, tal como um valor de verdade, funcionando no discurso da Justiça Restaurativa, a partir da análise de práticas discursivas na cidade de Porto Alegre/RS. Discurso que opera na lógica da inclusão de todos no espaço escolar, apostando na existência do funcionamento igual do humano e a escola tendo a função dessa formação. Uma inclusão que, ao mesmo tempo, afirma um "espaço de dentro" e um suposto "eu" das ciências humanas, agora atravessadas pelas ciências jurídicas. Vivemos uma biopolítica contemporânea que, buscando o gerenciamento do risco, mesmo que em potencial, produz um achatamento do que não se constituiu como mesmidade, na tentativa de garantir os "direitos de todos", pois este seria o preço cobrado pelo contrato da igualdade. Um discurso que funciona pela "defesa" das diferenças, trabalhada como o outro da identidade a ser resgatado e tornado igual. Uma biopolítica em nome da defesa da sociedade por meio do autogoverno num pan-óptico generalizado. E, junto a tais movimentos, poderíamos pensar em práticas de resistência que buscariam outras experimentações nesse campo educacional, tal como brechas de respiro, não para buscar instalar, então, uma verdade ainda mais verdadeira, mas justamente se colocando
\end{abstract} (CAPES).

${ }^{1}$ Trabalho financiado pela Coordenação de Aperfeiçoamento de Pessoal de Nível Superior

${ }^{2}$ Doutora em Educação pela Pontifícia Universidade Católica do Rio Grande do Sul (PUC/ RS). Pós-Doutora em Educação pela Universidade de Lisboa. Professora Permanente do Programa de Pós-Graduação em Educação da Universidade de Caxias do Sul. Professora da Rede Municipal de Ensino de Porto Alegre/RS, Brasil.

${ }^{3}$ Doutora em Educação pela Unversidade do Vale do Rio dos Sinos (Unisinos). Professora Adjunta da Universidade Federal do Rio Grande (FURG). Professora permanente do Programa de Pós-Graduação em Educação Ambiental e Educação em Ciências da FURG. Coordenadora do Programa de Pós-Graduação Educação em Ciências da FURG, Brasil. 
nesse jogo da verdade na problematização dos modos como estamos sendo governados e as implicações disso em nosso presente. Talvez um apostar em práticas pontuais, não generalizadas, desapegando-se de tantas identidades e encaminhamentos já disponíveis.

Palavras-chave: Justiça Restaurativa; igualdade; inclusão; escola.

\begin{abstract}
This article discusses the concept of equality, such as a truth value functioning in the discourse of Restorative Justice from the analysis of discursive practices in the city of Porto Alegre/RS. A discourse which operates in the logic of inclusion of everyone in the school space, which believes on an existence of human equal functioning, and the school having this compulsory formation. An inclusion which, at the same time, affirms an "inside space" and a supposed "self" of human sciences, now crossed by juridical sciences. We are living in a contemporary bio politics, which in the search for the risk management, even in potential, produces a flattering of what is not constituted as equal, trying to keep "everyone's right", because this would be the price charged by the equality contract. A discourse that works in the name of the "defense" of the differences, concerning this as the other of identity to be saved and became the same. A bio politics in the name of the defense of the society by means of self-government in a general panoptical. And, with those movements, should we think in practices of resistance which would search for other experimentations in this education field, such as a breach not to restore this way a truth still straighter, but specifically putting ourselves in this game of truth in the questioning of the ways as we have been governing and their implications into our present? Maybe these are a bet in punctual practices, still not generalized, detaching ourselves of so much identity and ways already available.
\end{abstract}

Keywords: Restorative Justice; equality; inclusion; school.

\title{
Falas introdutórias
}

O conceito de igualdade, tal como um valor de verdade, vem aparecendo em diferentes discursos que buscam tratar da inclusão no espaço da escola, tal como o discurso da Justiça Restaurativa, que, em uma contemporânea filiação com a educação, procura dar conta daqueles corpos que não cabem em relação à infração de leis e normas. Crianças e jovens que infringem normas na escola sempre existiram. O que há de novidade são as novas filiações que se propõem 
a restaurar esses indivíduos em nome da inclusão de todos. Trata-se de novas tecnologias de governo que buscam como fim último o autogoverno.

A Justiça Restaurativa (JR) no município de Porto Alegre apresenta-se como tendo o objetivo de pacificar violências, envolvendo crianças e adolescentes por meio de práticas da JR, operando com o conceito instituído pela ONU, que entende que: “A Justiça Restaurativa é um processo através do qual todas as partes envolvidas em um ato que causou ofensa reúnem-se para decidir coletivamente como lidar com as circunstâncias decorrentes desse ato e suas implicações para o futuro" (BRANCHER, s/d. p. 21).

A metodologia utilizada em Porto Alegre é a da Comunicação Não Violenta (CNV), a qual objetiva interações sociais pacíficas e seguras (BRANCHER, s/d.). Barter (s/d. p. 106) acredita que a CNV atue com os verdadeiros valores, argumentando que os atos de violência podem ser entendidos como expressões de necessidades não atendidas, elencando uma listagem com algumas necessidades humanas básicas, as quais todos teríamos, tidas como universais, tais como: honestidade, respeito, apoio, confiança, harmonia, ordem, paz, graça, entre outras. Nesse sentido, nos encontros restaurativos, as necessidades de todos os envolvidos necessitam ser levantadas, objetivando-se a autorresponsabilização e o cumprimento de um acordo por aquele indivíduo colocado na condição de ofensor, ou seja, aquele indicado pela "vítima".

Essa maquinaria opera com uma tecnologia específica: o Círculo Restaurativo (CR), constituindo-se em encontros com a participação da vítima principal e seus apoiadores, bem como a presença do ofensor e seus apoiadores, sob a organização de um coordenador, seguindo um roteiro predeterminado. Um encontro entre as partes envolvidas em um conflito e suas comunidades de apoio, a fim de se restaurar as relações, objetivando-se resolver o conflito por meio do diálogo, a partir de uma metodologia em que o coordenador do CR busca encaixar a fala das pessoas a necessidades universais não atendidas e das quais teria resultado o conflito. A partir desse diálogo, que pressupõe um consenso, chega-se a um acordo, o qual deverá ser cumprido, documentado, verificado e inserido nos sistemas de "segurança".

\section{O conceito de igualdade como um valor de verdade}

Essa maquinaria moral pressupõe um valor posto como dado: o da igualdade, o qual vem sustentado na JR pelo discurso das ciências humanas, das ciências jurídicas e do saber religioso, pois, "[...] a igualdade dos cidadãos 
perante a lei - eco da igualdade dos homens diante de Deus - não passaria de uma fórmula forjada por quem precisa somar forças para subsistir" (MARTON, 2001, p. 186). Filiações que operam com a função de definir, classificar e hierarquizar a normalidade e a anormalidade do humano, tornando esse humano inventado, medida para si mesmo e o inserindo em mecanismos de segurança.

Para Foucault (2004, p. 300), "através dessas diferentes práticas - psicológicas, médicas, penitenciárias, educativas - formou-se uma certa ideia, um modelo de humanidade; e esta ideia do homem tornou-se atualmente normativa, evidente, e é tomada como universal". Isso significa que um determinado modo de ser foi assumido como universal e uma moral estabelecida como sendo válida para todos. Nós, seres viventes, nos tornamos objeto para diversas ciências, amarrados a tecnologias políticas, a tecnologias de poder.

Esta crítica à ciência coloca-se como uma crítica a uma noção de verdade como valor superior que se produziu ao longo da história, a partir de uma lógica platônico-cristã. Assim, há uma estreita ligação entre ciência e moral, uma vez que é esta moral que dá valor à ciência. Os valores morais, como escreveu Nietzsche, não têm uma existência em si; são produções humanas. E como tão bem nos lembra Foucault, o regime político de verdade da nossa sociedade está assentado no discurso científico, nessa ideia de humanidade fabricada, a qual a escola teria a função de formar, sendo que a escola moderna constitui-se justamente no entrelaçamento das práticas disciplinares e biopolíticas para o controle da população.

Nesse sentido, parte-se do pressuposto do igual funcionamento do humano e busca-se essa formação como um objetivo. Uma igualdade que amarra o indivíduo a si mesmo, como que um encerramento em si, uma clausura do homem. Uma igualdade que democratiza o poder de julgar, que assume um rosto de controle, em que todos controlam a todos, como um grande pan-óptico generalizado. O processo nunca termina, no qual não se busca a punição, mas o controle, o autocontrole, tal como um conto kafkiano. Um sistema que documenta, organiza os dados, conecta o indivíduo a uma população, produz estatísticas do medo e da segurança em uma biopolítica contemporânea.

É neste cenário que o valor de igualdade é tratado como transcendental, como algo constituinte da natureza humana. O ideal moderno da igualdade é um dos princípios da ética moderna. A Revolução Francesa marca a história do ocidente, traçando princípios universais na busca do bem para a coletividade. Liberdade, Igualdade e Fraternidade são lemas que caracterizam a Revolução de 1789 e trazem lutas que intentam a garantia por direitos iguais, paz entre os homens e liberdade de expressão. Assim, tal revolução pretendia "a fraternidade dos povos e floridas efusões universais" (NIETZSCHE, 2001, p. 264), algo da ordem de uma coletividade de paz. Foucault (2002a, p. 23) nos lembra que: 
E, se é verdade que o poder político para a guerra, faz reinar ou tenta fazer reinar uma paz na sociedade civil, não é de modo algum para suspender os efeitos da guerra ou para neutralizar o desequilíbrio que se manifestou na batalha final da guerra. O poder político, nessa hipótese, teria como função reinserir perpetuamente essa relação de força, mediante uma espécie de guerra silenciosa, e de reinseri-la nas instituições, nas desigualdades econômicas, na linguagem, até nos corpos de uns e outros.

Não esquecemos que um dos instrumentos para se conseguir a paz, entendida como equilíbrio entre a pluralidade dos Estados no momento em que a racionalidade de Estado se organizava nos séculos XVII e XVIII, era justamente a guerra, que nesse momento, inclusive, se profissionalizava e se institucionalizava.

Recorrente e de grande prestígio na sociedade contemporânea, a igualdade tornou-se, na atualidade, uma questão indispensável, determinando certo modo de tratamento nos modos de existir no presente. A tentativa de garantir a igualdade de todos acaba por constituir uma espécie de achatamento de qualquer coisa que não seja a mesmidade. Contemporaneamente, a discussão da igualdade, enquanto valor ideal da modernidade, é pautada pela garantia de direitos e encarnada na proliferação constante dos discursos de inclusão. Assim, temos uma série discursiva que conecta três elementos, a saber, a igualdade como figura hegemônica de modernidade, o discurso da garantia de direitos na sociedade contemporânea e os discursos da inclusão no campo educacional.

Percebemos que os discursos da inclusão funcionam pela ativação do princípio da igualdade humana em geral e da igualdade de direitos perante a lei e, no caso da Justiça Restaurativa, retoma a questão da igualdade dos homens perante Deus. No entanto, a suposta "garantia" dessa igualdade opera em uma lógica de clausura do indivíduo dentro de si mesmo, desse humano médio do qual falava Nietzsche, em que aquilo que escapa é tomado como desvio, como falta a ser resgatada, como mais um modo de governo.

Trata-se de uma espécie de contrato de igualdade, no qual o preço cobrado é certo esquadrinhamento, certo modo de subjetivação. No caso da JR, isso se dando por meio de um controle que aprendemos a exercer conosco mesmo, por meio de tecnologias tais como a confissão, em que devemos reconhecer e expressar a verdade da nossa ofencionalidade em um determinado domínio moral, em que a consciência se faz jurídica. Confissão como um modo de saber que vem da ordem religiosa e é apropriado pelas ciências humanas e jurídicas, intimamente relacionado à administração da população. No processo de confissão da "verdade", no qual os indivíduos devem dizer a verdade sobre si mesmos 
para um expert avaliar, corrigir os desvios, declarar as punições ou prescrições, reforçar a norma, absolver, o poder se exerce justamente neste "fazer falar". Acredita-se que este é um processo que levaria a um suposto autoconhecimento, pois se trabalha em uma lógica de se chegar à verdade pela confissão e o indivíduo vai se produzindo nas próprias malhas desse discurso de igualdade.

Com essa busca pela igualdade, pelos direitos humanos - aliás, o que são direitos humanos senão a soberania de uma cultura em relação a outras? -, corre-se o risco de operar com a diferença como o outro da identidade, como uma diferença negativa que deve ser resgatada e tornada o mesmo, o igual, já que há toda uma busca por certo emparelhamento em nome de um mesmo tratamento legal, educacional, cultural etc. Por isso, talvez, o conceito que mais nos ajude a pensar seja o de diferença, que não significa diversidade ou variação humana, mas uma diferença que rompe com a identidade, como um modelo identitário e que opera sem recorrer a modelos referenciais. Não se trata de interioridade, de um eu, mas de invenções, de ficções, de efeitos, de inscrições. Como nos dizia Nietzsche (2006), não há o sujeito, apenas a ação. Os valores com os quais operamos têm uma história, que é a de batalhas, lutas e invasões, e a sua universalidade é mais uma fabricação desse mundo, sendo a própria verdade uma invenção que esqueceu que o é.

Nessa lógica de inclusão de uma diferença negativa, em que se opera com uma identidade normal, é garantido ao anormal ser "diferente" quando ele entra num aparato escolar institucionalizado, onde a "diferença" garantida é, ao mesmo tempo, a reafirmação, por contraste, da normalidade predominante. No entanto, nesse processo de institucionalização escolar da "diferença", a escola ainda permanece bastante "higienizada", como um espaço controlado, regido por certa norma de verdade, em que cada um deve aprender a ser humano de um modo geral e ainda deve aprender a ser o específico da posição que ocupa.

Trata-se de um quadriculamento em um pan-óptico generalizado, em que os mínimos comportamentos são agora não mais punidos, mas levados à autorresponsabilização, partindo-se do pressuposto do consenso, do acordo e da igualdade de funcionamento do humano, mas operando na demarcação de diferentes lugares que os indivíduos vítimas e ofensor, por exemplo, ocupam nessa maquinaria moral. A busca pela igualdade na diferenciação dos lugares, papéis e relações assumidas.

A normalização, então, como esse quadriculamento detalhado de cada um, em que se comparam os indivíduos entre si a partir da norma estabelecida para eles, marca os normais e os anormais, os desvios, já instaurando uma série de práticas para essa correção. Trata-se de um modo de regulação das condutas, assumidas como dada, natural e universal. E além desse modo de normalização 
disciplinar, digamos assim, podemos ainda pensar na lógica dos mecanismos de segurança, nos conceitos de "risco" e, em se tratando especificamente da Justiça Restaurativa, de "risco em potencial", no qual a norma não está dada a priori, mas a partir do estudo da coletividade, da distribuição dos casos, calculando-se o risco e marcando-se o que é perigoso.

Com a busca pela garantia de igualdade, o pensamento do mesmo, grande matriz da modernidade, torna evidente seus rastros no discurso da Justiça Restaurativa na busca incansável pela igualdade, fazendo o "Outro, o Longínquo [ser] também o mais Próximo e o Mesmo" (FOUCAULT, 2002b, p. 469).

Desta forma, nesse campo discursivo, fica difícil entender que a nossa linguagem, a nossa cultura, os nossos valores não são toda a linguagem, toda a cultura, todos os valores e tão pouco se constituem em um centro através dos quais os demais devessem girar ao redor. Assim, não há espaço para aquilo que não cabe na nossa linguagem, na nossa forma de racionalidade, na nossa cultura. Já temos nome para quase tudo, já temos os encaminhamentos, os especialistas, os espaços geridos e as identidades gerenciadas, como trazem certas práticas discursivas da JR.

Os discursos da inclusão consolidam essa pretensão: um dia todos serão incluídos, todos farão parte, nada e ninguém ficará fora do grande projeto moderno de conhecimento e domínio do mundo. Todavia, essa espacialidade do dentro e do fora também pode ser entendida como mais uma invenção moderna, em que, como nos traz Skliar (2003, p. 93, grifo do autor), "o excluído é somente um produto da impossibilidade de integração. Não é um sujeito, é um dado. É a negação do estar dentro que serve, ao mesmo tempo, como uma afirmação desse espaço dentro", ou seja, dessa escola tal como está posta, desse suposto "eu". Para o autor, (SKLIAR, 2003, p. 94, grifos do original),

A relação exclusão/inclusão é, à primeira vista, uma das mais típicas representações espaciais, territoriais a partir da qual foi exercida uma pressão sistemática para organizar o mundo (e a cultura, e a educação, e a política etc;): há indivíduos que estão fora do mapa (o outro excluído), o que supõe necessariamente a existência de indivíduos dentro desse mapa (o outro incluído que é, na verdade, um eu mesmo incluído).

Estar incluído, nesse sentido, poderia significar muitas coisas: estar normalizado, estar disciplinarizado, estar regulamentado, estar cooperando com as malhas institucionais. E, principalmente, não ser um perigo para a sociedade, mesmo que em potencial. 
Inclusão como esse dispositivo escolar de trazer para perto o indivíduo que se encontra fora da ordem, para que se organize um saber a seu respeito, para que se possa geri-lo dentro de uma dada norma, evitando-se com isso os riscos que o mesmo apresentaria se estivesse longe. Inclusão para o esquadrinhamento, restauração, normalização.

A inclusão e a exclusão podem ser pensadas com Foucault (2001) como fazendo parte de uma mesma matriz de poder, ambos como subprodutos do racismo de estado, de governar o outro, de uma lógica de controle da população, seja "excluindo" para longe, tomando distância, seja "incluindo" em práticas de inspeção e dados quadriculados, trazendo para perto para melhor conhecer e governar. A proveniência desses conceitos é "esquecida" e o conceito de inclusão é tratado usualmente como "bom" e "isento de relações de poder", isto é, colocado para funcionar em uma lógica metafísica.

O próprio termo "inclusão" pode ser lido como "fechar por dentro", o que nos leva a pensar em fixação a uma identidade, a uma norma, amarrando o indivíduo a ele mesmo, à sua suposta interioridade, à sua suposta humanidade, à sua suposta igualdade, tão proclamada nas práticas discursivas da Justiça Restaurativa.

Assim, demonstrando que a igualdade não é uma condição natural, Nietzsche declara que é através da condição de desigualdades que se força uma condição de igualdade. Através do direito legal, garantimos a igualdade de todos. A igualdade então elimina tudo que é da ordem da diferença. Para Marton (2001, p. 186),

Promotor da vida em coletividade, o indivíduo mais fraco em momento algum poderia abrir mão [da igualdade]. Por isso, instituiria maneiras de agir e pensar universalmente válidas, censuraria toda originalidade, reprovaria qualquer mudança. Exigiria ininterruptamente a vitória de cada um sobre si mesmo, para que a sociedade se fortalecesse. Igual entre iguais, o animal de rebanho talvez até cresse que os homens são todos irmãos.

Para Nietzsche, a igualdade é uma astúcia dos fracos para se manterem em condição de equivalência. Na vida pública, então, criamos estratégias para organizar a vida de modo a garantir a todos os mesmos direitos. Para isso, precisamos nos fazer parecidos, que sejamos iguais perante a lei, expurgando tudo aquilo que é da ordem da diferença, que coloque em xeque a nossa tão desejada condição de irmãos. Com a ajuda de Marton (2001), podemos pensar nesse conceito de igualdade na lógica em que Nietzsche nos fala, isto é, na necessidade 
dos fracos se filiarem, e seria desse modo que o direito teria surgido, pois com ele, ao invés do embate, do confronto, agiriam com prudência, esperando que os demais reconhecessem seus direitos e permitissem conservá-los, mantendo, desse modo, as relações de força. Assim, "meus direitos seriam essa parte do meu poder que os outros reconhecem e me permitem conservar; meus deveres, os direitos que os outros têm sobre mim" (MARTON, 2001, p. 185).

A Justiça Restaurativa, pois, opera com um suposto humano que habitaria em cada um de nós, um sujeito dado, com uma interioridade, descrevendo este humano como falho e vulnerável, sendo que devemos ser humildes para aceitar essa suposta condição universal, o que permitiria unir vítima e ofensor pela "condição humana" de serem seres defeituosos, por essa condição de igualdade da mediocridade. Um humano cristão e mais ainda, estragado, defeituoso, fraco, que busca filiação pela fraqueza, pela condição de vulnerabilidade e defeituabilidade. É a produção do sujeito médio, medíocre, ressentido. Um humano criado à semelhança de Cristo e que por isso deveria ser grato, humilde, servo, em que a vida é depreciada em nome de valores superiores. Como nos traz Nietzsche (2005, p. 170),

[...] somente o animal de rebanho recebe e dispensa honras, quando a "igualdade de direitos" pode facilmente se transformar em igualdade na injustiça: quero dizer, em uma guerra comum a tudo que é raro, estranho, privilegiado, ao homem superior, ao dever superior, à responsabilidade, à plenitude de poder criador [...].

Não queremos com isso fazer a defesa de uma sociedade sem parâmetros de regulação da ordem social ou sem valores, um vale-tudo, porque a questão não é não se ter valor, uma vez que os valores não são bons ou ruins em si mesmos. A questão está em discutir as "evidências", mostrar a arquitetura dessas fabricações, daquilo que vem sendo apresentado como natural. Mais do que "derrubar" valores e códigos, uma postura de problematizar nossas relações com eles.

Desse modo, a igualdade pode ser pensada, como uma possibilidade de análise, muito mais como uma estratégia que, longe de resolver as desigualdades, funciona como um contrato que estabelecemos para tentar equalizar o mundo, produzindo efeitos de verdade, operando em uma lógica que continua fabricando discursos proferidos como imprescindíveis para vivermos no mundo atual, tais como as práticas da Justiça Restaurativa na luta pelo bem.

Uma igualdade que dá a cada um o seu lugar e que o amarra a essa identidade. Pois, como nos traz Skliar (2003, p. 196), 
Afirmamos que estamos diante de um novo sujeito. Mas é preciso dizer: de um novo sujeito da mesmidade. Porque se multiplicam suas identidades a partir de unidades já conhecidas, extremam-se os nomes sobre nomes já pronunciados. Somente alguns poucos retalhos de sua alma são autorizados, respeitados, aceitos, tolerados.

Vivemos os sintomas de uma sociedade de controle, de defesa da sociedade de que trata Foucault (2001), mas defesa de uns contra outros, contra os indivíduos tidos como perigosos, mesmo que em potencial, como nos casos de infração às normas por alunos na escola, em que são tomados como possíveis infratores às leis no futuro.

O conjunto das práticas acaba, então, capturado pela lógica que Foucault descreve como o pensamento do mesmo, ainda que a referência mais explícita seja a fala em prol das diferenças. Há como que uma "diferença permitida", aquelas administráveis, toleráveis, gerenciáveis, como aparece nas falas da JR; uma diferença sempre marcada pela negação que impõe a identidade, o mesmo.

As diferentes políticas de inclusão na escola, tal como a Justiça Restaurativa, muitas vezes se colocam na "defesa da diferença", mas não discutem o predomínio e a hegemonia da lógica do mesmo, na qual a convivência humana já está dada, prescrita e calculada. Quando há um "elogio" às diferenças não se rompe, necessariamente, com os valores modernos tidos como metafísicos, pois se faz esse "elogio" a partir do mesmo solo: o da igualdade. O que se pretende ainda é fazer uma adequação da sociedade frente à moralidade posta como verdadeira, agora, talvez, com estratégias tanto mais flexíveis quanto eficientes. O mundo contemporâneo caminhou na direção de sua flexibilização, de seu amolecimento e, com isso, foram geradas novas tecnologias de controle social - boa parte delas direta e irremediavelmente dependentes dos saberes científicos que continuam determinando os modos adequados de conhecer, de pensar, de ser.

Problematizar essa biopolítica contemporânea, que pode ser analisada nas práticas da Justiça Restaurativa, nos leva na direção de entender que são acionados diferentes modos do poder se exercer, reunindo técnicas disciplinares, tais como o exame e a confissão, assim como técnicas de regulamentação que se debruçam ao controle dos indivíduos organizados em população. Um poder massificante que atua no corpo social, gerenciando e defendendo a ordem para o convívio na sociedade. Uma biopolítica que se complementa com técnicas disciplinares, em um contemporâneo pan-óptico generalizado, em que o controle está espalhado por todo o corpo social. Aqui se oferecem novas filiações que se dão na junção das ciências humanas e das ciências jurídicas, da pedagogia e da Justiça Restaurativa na escola, como novos modos do governo se exercer na 
condução das condutas, sendo a questão da segurança da população uma das condições de possibilidade para esse regime de verdade.

O discurso da inclusão, pois, torna-se um projeto de proteção e ordem, como um projeto de defesa social (FOUCAULT, 2001). O projeto de defesa social cria na contemporaneidade diferentes estratégias de proteção e controle ao perigo, reunindo a educação formal e o poder judiciário a serviço desse projeto, como uma das estratégias de normalização.

Trata-se de uma contemporânea biopolítica, em que percebemos o quanto os discursos da igualdade que circulam nas práticas de inclusão se configuram, agora, com outras estratégias para o gerenciamento do risco social, organização, o gerenciamento e o controle da população. Regulamentação, prevenção e cuidado são as preocupações da atual sociedade na busca de garantir a vida em coletividade. Por isso, a preocupação agora não é somente com o controle das epidemias que acometiam a sociedade, produzindo inúmeras mortes. As forças são agora canalizadas também para endemias, aquelas "doenças mais ou menos difíceis de extirpar, e que não são encaradas como as epidemias, a título de causas de morte mais frequente, mas como fatores permanentes" (FOUCAULT, 2002a, p. 290). Diferenças que não podem estar simplesmente soltas no mundo, mas é preciso controlá-las para que não gerem ameaças à regularidade da população, em seus modos de saber e conviver.

O que entendemos desses discursos é bem mais que uma ativação pela igualdade de todos, mas uma ordem que "funciona essencialmente como defesa social" (FOUCAULT, 2001, p. 404). Diferentemente de uma bandeira de todos os brasileiros, percebemos o discurso da inclusão como uma tentativa incessante de defesa social, ambicionando a inclusão domesticada de todos. Um movimento de civilização de todas as forças que fujam aos modos convencionais de saber e conviver prescritos pela moral posta.

\section{Algumas considerações}

A igualdade se consolida na atualidade, então, tendo-se como um forte regime de verdade o discurso da Justiça Restaurativa, operando com duas questões primordiais: a garantia de direitos e os discursos da inclusão na educação ou via a educação, sustentada pelo pensamento do mesmo. Um aplainamento em nome dos direitos humanos universais, em nome da inclusão compulsória, da justiça, em nome da igualdade natural. 
Com tais problematizações não estamos querendo dizer que somos contrárias às políticas variadas de "inclusão", mas pontuar a importância de se colocar a pensar a respeito deste conceito, de como ele se torna um forte regime de verdade em nossa época e o que vem produzindo em se tratando de modos de subjetivação. Questionar os limites disso pode ser entendido como buscar entender o que estamos nos tornando no presente e por meio de quais verdades estamos aprendendo a nos relacionar conosco mesmo.

Talvez um apostar como que em uma outra ética, em que se problematiza o discurso científico unitário, apostando em lutas locais, na singularidade dos acontecimentos. Não se trata de desvendar uma verdade metafísica de um sentido, mas mostrar as estratégias de produção dos efeitos de verdade. Não estamos lidando com essências, mas práticas tais como a da Justiça Restaurativa, que obedecem a determinados tipos de racionalidade e que produzem determinadas formas de ser sujeito que são assumidas em exercícios de poder e efeitos de verdade.

Mas onde há poder, há resistência, como nos traz Foucault (1995). E como as relações estão espalhadas por toda a teia social, as lutas não podem vir de fora, pois será sempre resistência dentro das próprias malhas de poder. Trata-se de pontos móveis e que vão sendo capturados e assim vivemos esses movimentos de invenção e resistência, de novas capturas e novas resistências, uma vez que o presente é contingente e pode ser pensado de outras formas.

Não se trata de uma nova bandeira de ser "antitudo", de não se ter valor algum, da militância pela mudança a todo momento, muito menos uma busca por uma verdade, então, final. Não se trata disso. Significa entrar no jogo da luta, do questionamento das evidências. Um processo permanente de crítica dos modos como estamos nos constituindo no que somos e em nossas capturas, no tencionamento conosco mesmo, com nossa cultura, com as instituições nas quais circulamos, nas relações com os outros, com nossos saberes, colocando em cheque o modo como estamos sendo governados, de como governamos a nós mesmos. Um implicar-se com o presente, experimentando outras possibilidades para além das identidades já disponíveis.

\section{REFERÊNCIAS}

BARTER, D. Comunicação não violenta: uma base ética para práticas restaurativas. In: Justiça para o século XXI: instituindo Práticas Restaurativas. Material de apoio - Curso de Formação em Práticas Restaurativas. Mimeo. Texto integrante da publicação "Justiça 
Restaurativa", da Secretaria da Reforma do Judiciário, Ministério da Justiça e PNDU, s/d. Disponível no site www.mj.gov.br.

BRANCHER, L. Justiça para o século XXI: instituindo Práticas Restaurativas - Iniciação em Justiça Restaurativa. Mimeo. Porto Alegre, s/d.

FOUCAULT, M. O sujeito e o poder. Apêndice da segunda edição. Michel Foucault entrevistado por Hubert L. Dreyfus e Paul Rabinow. In: DREYFUS, Hubert; RABINOW, Paul. Michel Foucault, uma trajetória filosófica: para além do estruturalismo e da hermenêutica. Rio de Janeiro: Forense Universitária, 1995.

. Os anormais: curso no Collège de France (1974-1975). Tradução de Eduardo Brandão. São Paulo: Martins Fontes, 2001.

. Em defesa da sociedade: curso no Collège de France (1975-1976). Traduzido por Maria Ermantina Galvão. São Paulo: Martins Fontes, 2002 a. (Coleção Tópicos).

. As palavras e as coisas: uma arqueologia das ciências humanas. 8. ed. São Paulo: Martins Fontes, 2002b.

. Ética, sexualidade, política. Organização e seleção de textos: Manoel Barros da Motta. Tradução de Elisa Monteiro e Inês Autran Dourado Barbosa. Rio de Janeiro: Forense Universitária, 2004. (Ditos e Escritos; V).

MARTON, S. Extravagâncias: ensaios sobre a filosofia de Nietzsche. 2. ed. São Paulo: Discurso Editorial e Editora Unijuí, 2001. (Sendas \& Veredas).

NIETZSCHE, F. A gaia ciência. Tradução de Paulo César de Souza. São Paulo: Companhia das Letras, 2001.

. Além do bem e do mal: prelúdio a uma filosofia do futuro. São Paulo: Companhia das Letras, 2005.

. Genealogia da Moral: uma polêmica. 9. reimpr. Tradução de Paulo César de Souza. São Paulo: Companhia das Letras, 2006.

SKLIAR, C. Pedagogia (improvável) da diferença: e se o outro não estivesse aí? Tradução de Giane Lessa. Rio de Janeiro: DP\&A, 2003.

Texto recebido em 13 de outubro de 2009.

Texto aprovado em 25 de janeiro de 2010. 